\title{
The Cult of Victorianism: Eating Disorders and Graphic Medicine
}

\author{
Sathyaraj Venkatesan ${ }^{1} \&$ Anu Mary Peter ${ }^{2}$ \\ ${ }^{1}$ Assistant Professor, Department of Humanities and Social Sciences, National Institute of \\ Technology, Tiruchirappalli, Tamil Nadu, India-620015, sathya@nitt.edu, oooo-0oo3-2138- \\ 1263. \\ ${ }^{2}$ Research Scholar, Department of Humanities and Social Sciences, National Institute of \\ Technology, Tiruchirappalli, Tamil Nadu, India-620015, anupeterthekk@gmail.com,oooo- \\ ooo1-6740-8252.
}

Received October 05, 2017; Revised November 18, 2017; Accepted November 30, 2017; Published December 09, 2017.

\begin{abstract}
Eating disorders in women can be identified as a devastating repercussion of the punitive cultural norms of feminine restrictions practiced in the Victorian era. By close reading Karrie Fransman's graphic narrative The House That Groaned (2012), the present paper foregrounds the abiding and irrefutable presence and influence of Victorian concepts of restrictive eating in the post-millennial era. Borrowing theoretical postulates from Susan Bordo, Susie Orbach, and Deborah Lupton this article seeks to investigate the subterranean cultural connections between these two centuries. Considering eating disorders as a detrimental cultural denouement of Victorian chauvinism, the article also examines how Fransman's adept utilization of the stylistic and structural affordances of the medium of comics vis-à-vis temporality, gesture, speech balloons, light, and color creates a verbo-visual assertion of the subjectification/ objectification of women.
\end{abstract}

Keywords: eating disorder, Victorian era, food, eating, sexuality, liberation, restriction.

\section{The House That Groaned as a Representation of Cultural Anxieties}

Published in 2012 by Square Peg, Karrie Fransman's debut graphic narrative, The House That Groaned is a topical elucidation of the subjectification of a female body. Written with the prime objective of sketching out a "good story" (Alderson, 2012), the graphic narrative is introduced to readers from the perspective of Barbara, the new inhabitant in Godfrey's Building at 141 Rottin Road. As a chromosome of the contemporary society which is affected by eating disorders and other issues pertaining to the cultural incarceration of female bodies, the story revolves around six characters with clandestine past-Barbara, a human Barbie; Janet, a tormented dietician suffering from anorexia; Marion, a hedonist; Durbach, an old widow; Matt who airbrushes models in magazine and Brian, a diseasophile. Through these characters, the graphic narrative, which also doubles as an urban gothic brings to relief the oppression and silencing of female body specifically by citing pertinent cultural issues such as feminine eating disorders, the societal obsession with feminine beauty and also the idea of women as an object of pleasure. Stylistically, visually intense

(c) AesthetixMS 2016. This Open Access article is published under a Creative Commons Attribution Non-Commercial 4.0 International License (http://creativecommons.org/licenses/by-nc/4.o/), which permits non-commercial re-use, distribution, and reproduction in any medium, provided the original work is properly cited. For citation use the DOI. For commercial re-use, please contact editor@rupkatha.com. 
and dim-lit panels of the narrative, doused in a greenish grey shade succinctly captures the isolation and powerlessness experienced by women with eating disorders.

Apart from the six main characters, the house itself is a silent character which occasionally intrudes into the life of its inmates through ghastly noises and leakages. The house is introduced to the reader as a "cosy. . . [and] charming Victorian conversion" (n.p) through an advertisement on the very first page of the graphic narrative. In so doing, the author subtly associates the house with the Victorian era and its attendant ideologies, especially the Victorian double standard. Alerting the readers, as it were, to a plethora of meanings, Fransman states that her graphic narrative "only make[s] sense on a second reading" (Alderson, 2012). Followed by consistent warnings about its concealed dilapidation, the house collapses with most of its inmates towards the end of the narrative. As such from the cut-work cover to the last page, the materiality of the book is skillfully utilized in presenting and performing the book as a house in actuality.

Beyond the explicit deliberation of body politics, The House That Groaned is also a cultural reading of female body from a Victorian perspective in that, the narrative perspicuously mirrors the remnants of Victorian proclivities in contemporary society. Reflecting the hypocritical social codes of the nineteenth century through its characters who are marked by their bodily idiosyncrasies, The House That Groaned critically examines female body as a "canvas on which anxieties and discourses of the larger, social body are reproduced" (as cited in The Body as a Canvas in Comics, 2012). Illustrating how women continue to be victims of antiquated cultural norms, The House That Groaned delineate the adverse impact of Victorian ideals of beauty and eating on women and thereby characterizes eating disorders (especially anorexia nervosa) as a consequence of the rigid cultural practices exercised upon women.

\section{Victorian Era and Pseudo Morality}

Choreographed as a time of exemplary standards, Queen Victoria's reign was also a time of contradictions forsooth, which led to the remorseless quashing of women's genuine aspirations under the aegis of Victorian decency. In accordance with the popular cultural conviction that body mirrors the unvoiced impulses and emotions of a person, Victorian society gave implausible significance solely to women's physical appearance. As a result of their false fetish for propriety, Victorian society was characterized by specious rectitude, debauchery, mendacity and the egoistic pursuit of pleasures. One notable instance of Victorian prudery is the displacement of the symbolic meaning of feminine hunger with that of sexuality. In the highly patriarchal Victorian society, voracious eating was considered as an exclusive social symbol of Victorian manliness, whereas it was a cultural marker of shame for women. As Helena Michie (1990, p. 13) observes, "women's hunger operates with equal force in interstices of Victorian culture." Having high regards for pure women, Victorian society trained its women to restrict their eating in order to become ideal women.

Interlaced with the cultural norms of virginity, "delicate appetite" (Michie, 1990, p. 16) was perpetuated as a symbol of elitism among Victorian women. Thus, more than a mere lifesustaining endeavor, eating also had various other ludicrous interpretations among Victorians. Essentially, the cultural notions of femininity became predicated on food and eating. As Michie (1990, p. 17) observes, "the portrait of the appropriately sexed woman, then, emerges as one who eats little and delicately." Along with appetite, feminine desires also underwent cultural screening. In a society which considered thin and pale women as graceful and pure, denial of food or restriction of expressions of likeness for food was an avowal of feminine grace. In essence, by 
giving unreasonable importance to feminine fragility, the Victorian society disciplined its women to "face the dinner table with ladylike anorexia" (as cited in Michie, 1990, p. 20). While restricted food intake was apparently to "enhance the symbolism of wholeness and purity" (Michie, 1990, p. 21), the Victorian corsets and stiff lacing were used for curtailing and silencing women on a physical as well as intellectual level.

It wasn't uncommon but adventitious when the Victorian culture began to interpret the hunger of the female as a sly metaphor for sexual appetite which Michie (1990, p. 13) contends rightly as a "Victorian euphemism." Feminine hunger was strategically reconceptualized and recognized as a strong biological symbol of their sexual longings, and therefore the ideal Victorian woman was culturally stipulated to disavow her hunger. Abstracting the ideation of food and sexuality as "the unseemly show of desire" (Bordo, 1997, p. 112), women began to be considered salacious if they loaded their plates. Resultantly, Victorian women practiced restrictive eating and they were warned against indulgence as well as any expression of desire for both food and sex. Thus, in Victorian society hunger was radically immersed in gender politics. In her Unbearable Weight, Bordo notes that it is from the Victorian era that the western society started to equate women to body perfection and beauty ideals. Predicated on certain antediluvian gender ideologies, the present-day societal expectations from a woman to restrict food/sex is thus a corollary of the Victorian ambivalence.

Perpetuating the Victorian concept of normative femininity through psychological subterfuges, the enfeebling of women was a gendered gambit meant to foster men's supremacy. As Michie (1990, p. 20) states "the aesthetic of weakness and hunger . . . disguises an ideology of male dominance." Intriguingly, when the early nineteenth-century patriarchy considered feminine hunger as a metaphor for sexual appetite, it also engendered in men the notion of a necessity to annihilate feminine desires. Therefore, restricting women was more of a cultural desideratum. Developed as a "counter-offensive" (Bordo, 1993, p. 115) against the liberated women of modern society, Victorian women's eating habits were a lucid reflection of their oppression. In essence, the metaphorical sexualizing of unrestrained eating is highly suggestive of the Victorian ideation of food as the symbol of liberation. In demarcating the eating style of men and women into two variant standards of social acceptance, Victorian society was creating a cultural understanding of eating behaviors in accordance with the prevailing gender politics. Trying to solve the spurious equation of appearance and happiness, women are still struggling to establish body as an answer to the cultural questions, giving way to the rise of an exceedingly anorectic women population.

\section{“Am I hungry? Am I full?": Clinical and Cultural Perspectives of Anorexia Nervosa}

Closely associated with the questions of selfhood and social roles, anorexia nervosa is an eating disorder that occurs due to the fear of weight-gain and low body image. Anorexia usually begins during adolescence and is rampantly seen in women. Signalized by a relentless pursuit of thinness, extreme fear of obesity, body image distortion and restricted food consumption, anorexia nervosa is a psychopathological disorder which is characterized by disruptive eating patterns that lead to a low body weight or sometimes even death. Anorexics restrict food intake even after achieving the desired weight resulting in life-threatening consequences. Although in modern times self-starvation is medically categorized into anorexia nervosa and treated as a psychological disorder associated with food habits, it was considered as a miracle in the Victorian 
era. However, beyond the clinical understanding of anorexia as an eating disorder, it is a psychological condition associated with beauty myths and ideals of the perfect female image.

In the cultural definitions of femininity that appraises obesity as unattractive and undesirable, the predilection to be thin is endemic. Malson and Ussher (1997, p. 45) maintain that eating disorders are a "manifestation of a multiplicity of contemporary socio-cultural concerns, for example, about gender politics, individual control and consumption." When the pursuit of thinness became part of a search for identity, establishing control over the body became significant. Worse still, a state of constancy develops where the control between the person and her body gets reversed, such that the body controls the thoughts, feelings, and actions of the person in an uncanny and life-threatening way. Informed by the cultural abstractions of all centuries, femininity and its chaotic concatenation with beauty has always been at the center of all societies. This reaffirms Brumberg's remark that "body [is] still a girl's nemesis" (1997, p. Xxv). More than ever, women in the latter half of the nineteenth-century were under more cultural and corporeal pressure and therefore at a greater risk too. Due to a "unique combination of biological and cultural forces" (Brumberg, 1997, p. xxv), the female body has inevitably become a site of cultural apprehensions and obsessions. Though a clinical reality, anorexia is a repercussion of certain socio-cultural ideologies and cultural forces. As an appropriate cultural representation of the contradictory norms of the Victorian era, the house and its inhabitants in The House That Groaned perspicuously embodies these ideologies.

\section{"That's quite enough, Janet!": Food as a Means of Oppression}

In the Victorian society, the concept of eating was used as a strategic tool to reinforce male sovereignty. Considering eating as a strange symbol of liberation as aforementioned, the Victorian male society understood restriction from food as a duplicitous way to control women and the possible threats that the intellectually liberated women can pose to the prevalent gender hierarchy. Predicated on clear gender ideologies, Victorian society considered that “women's sexual appetite must be curtailed and controlled" (Bordo, 1993, p. 117). As a result, physical appearance became an integral factor in the way women constructed themselves. Intriguingly, this notion was transmitted from generation to generation by women themselves. Thus, Victorian ideations have a clear connection with the rise of eating disorders, where "the promotion of restrictive eating contributed to women's systematic denial of food ingestion, which manifested the Victorian cultural milieu of anorexia" (Chou, 2011, p.192). Thus, food and eating were successfully devised as a psychological trick to confine feminine ambitions to their body itself and this traditional method of oppressing women through food habits continues even today. As Brumberg rightly observes, the female body is "a template for much of the social change of twentieth century" (1997, p. xxv). Interestingly, against mainstream modes of verbal or visual representation of female oppression, there is a freedom that the medium of comics provides to the artist. As Orbach contends, "a woman's body is one of the few culturally accepted ways a woman has to express herself" (1978, p. 189) and comics procures a safe space for women to express their cultural and corporeal anxieties. In The House That Groaned, Fransman graphically depicts the oppression suffered by women with eating disorders through complex visual techniques such as the noirish color tone, shadows, panels of unconventional size and shape.

In The House That Groaned, Janet Miller, the dietician's mother can be identified as the voice of the Victorian society which ordained women to restrain their appetite. Followed by her marriage with Adam, Janet is threatened by her mother to be "frugal and plain" (Brumberg, 1988, 
p. 179). The mother also cautions Janet by saying "now you have a husband to worry about Janet!" (n.p). Snatching away Janet's plate while she was yet to finish, the mother reminds Janet that it is the duty of an ideal wife to maintain a perfect body in order to impress the husband. Thus, in the contemporary society, Janet becomes a victim to the attendant Victorian beauty ideals as she painstakingly appropriates herself to the ideology through strict diet plans and strenuous exercises. As she starts to believe in the classic cultural construct that "slim is beautiful" (as cited in Unbearable Weight, xiv); through strict exercises and diet plans she also reflects how women are shackled by popular body-beauty myths perpetuated as early as in the Victorian era. Later, Janet educates the members of her diet class by saying that "you can trick the mind by eating your dinner on smaller plates to make your portions look bigger" (n.p). Thus Janet's corporeal and psychological struggle could be seen as an echo of the Victorian culture which was dictating food habits and shaping desires of the then society.

\section{“Let us liberate our bodies!": Food as a Means of Liberation}

Concurrently, in The House That Groaned, the author also addresses the other side of the Victorian ideal which cerebrated food as a symbol of liberation. Deftly capturing the gluttonous ways of Marion, the hedonist, Fransman describes the feminine rebellion against the oppression of women using body and food. Unlike other characters in the book, the author introduces Marion's voice in precedence to herself through the midnight phone call that Janet receives at the beginning of the narrative. Self-defined as 'the voice of liberation', Marion is a creative personification of the Victorian feminine psyche which yearned for freedom from the cultural fetters that tethered women to a state of servility to men through meager food, tight corsets, sexual oppression, lack of independence to name a few. Utilizing the amenability of comics, the chosen medium, the artist adroitly depicts the motive of liberation through its stylistic and structural features in The House That Groaned. As J. Maggio (2007, p. 238) in "Comics and Cartoons: A Democratic Art-Form" contends, "the art forms of comics/ cartooning has an inherent element of democracy. . ." Stylistically, the free-sized panels perform the emancipatory ideals of Marion while the panel borders reflect the restrictive social norms at the level of structure. Similarly, oversized panels that are used to accommodate obese individuals also evinces the capacity of the medium of comics to represent the excessiveness of binge eating. The inflated speech balloons are thus, the visual embodiment of Marion's voice of cultural freedom, sexual liberation, and unbridled esurience. Apart from the structural aspects of free-sized panels, presence or absence of borders, certain techniques such as emanata, figural drawings among others add to the effective cultural mapping of the liberation of the female body through food.

Marion's physical appearance, voice, and actions reflect her idée fixe with disenthrallment thereby presenting herself as the verso of Janet - the woman who was silenced and tamed with oppressive ideologies. While journeying through her past, readers understand how Marion's childhood portrays herself as a girl with "pretty strong opinions" (n.p). Foregrounding the chaotic impact of social restrictions on females, Marion exhorts her schoolmates to rise in rebellion against the social setting by saying, "[w]e are fed up of being made of sugar and spice. Of wearing pretty little uniforms and silly little hats" (n.p). Accordingly, Marion's retort that "we are fed up of having our bodies constrained by society's demands!" (n.p) is a strong comment on the Victorian fixation on female corporeality and gender roles. Plausibly, Marion's call for rebellion culminates with an invitation to unfetter the feminine ties from social demands as she says "[c]ome! Let us shed these uniforms! Let us liberate our bodies!" (n.p). Challenging the socio-cultural boundaries based on gender, Marion iconoclastically challenges the female submissiveness to the demands of 
the patriarchal society by encouraging some of the characteristics of a Victorian man - freespiritedness, voracity, and lasciviousness. In so doing, Marion emerges as a converse of the postmillennial women who are victims of body perfection and beauty ideals.

\section{"charming ... newly decorated": Victorian Hypocrisy and The House That Groaned}

In similitude with most of the characters in The House That Groaned, the house which is a 'silent' character that 'groans' from the heft of pseudo-Victorian ideals also reaches a catastrophic climax. Right from the "die-cut cover [that] draws in like a voyeur" (Alderson), Fransman exploits the architectural specificities of the building to parallel the ideologies foregrounded by the book (see Figure 1). With all of its anachronistic and artificial embellishments such as sash windows, brick walls and roof with slate tiles, the mansion manifests some of the ineludible contradictions of the Victorian society. Presented to the reader through an impressive advertisement, both the book and the house are evinced as a "charming Victorian conversion" (n.p). Although advertised as "cosy" and "newly decorated" (n.p) the actual state of the house is soon exposed through various inmates' perspective of the house as uncomfortable, ghastly and delusive. Characterized by loose living against the contesting puritanical perfectionism of Victorian era, the apartment in Godfrey's Estate exhibits inherent contradictions. Against the jacket cover that takes the guise of the impressive outward view of a Victorian mansion, the book exposes its destruction, ruination, wreckage, and leakage in the following pages.

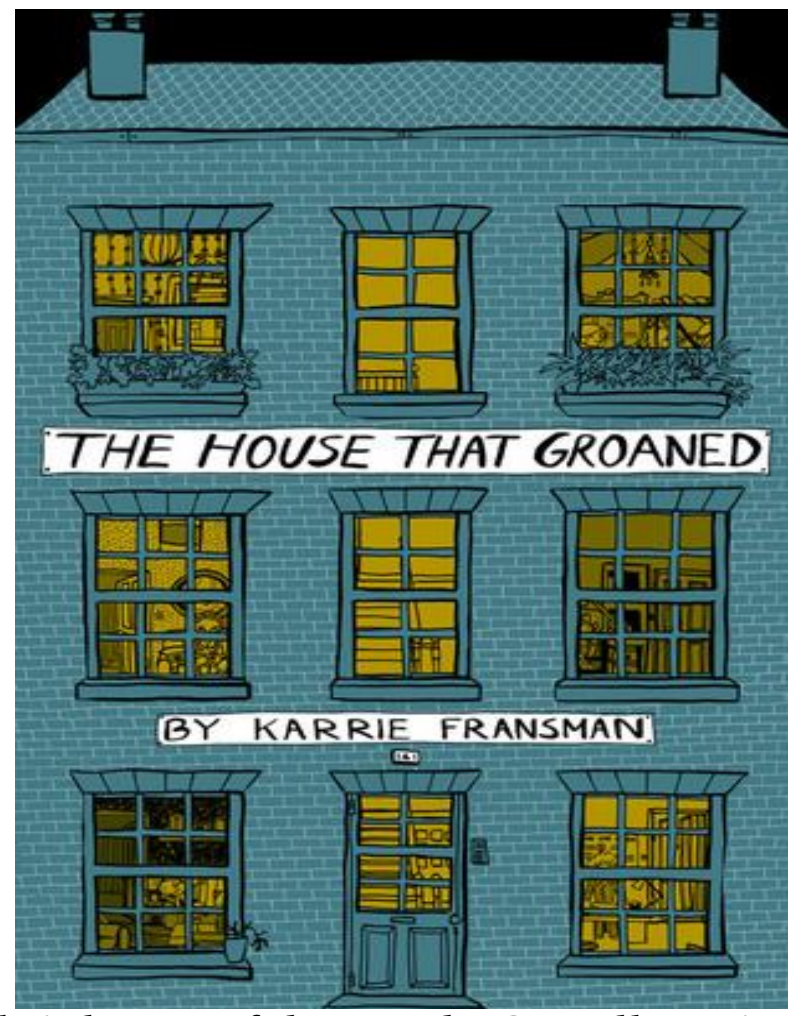

Figure 1: The jacket cover of The House that Groaned by Karrie Fransman.

Interestingly, while the cut-work cover presents 141 Godfrey's building and the inmates with all its majesty, the inner cover page astoundingly expose the actual life of each character. The cover not only conceals the dilapidations of the house but also the private lives of each inhabitant (see Figure 2). Durbach's room, for instance, pictured from outside as the most beautiful one with 
fancy lights and decorations disguise the uneventful and unwanted life of the old widow. Similarly, the alluring chandelier and party-mood seen through the very next window deftly hide the obscenity, gluttony, and revelry of 'Midnight Feast Front', the quasi-food/sex orgy conducted at Marion's place. So is Brian's well-kept room which conceals the life of a pervert and a diseasophile. Ultimately Janet's office room although stunningly captures her disciplined life, also skilfully hides the over disciplined and strained life of an embittered divorcee. Thus, by portraying the macrocosm of a society characterized by contradictory ideals, The House That Groaned is a commentary on Victorianism itself.

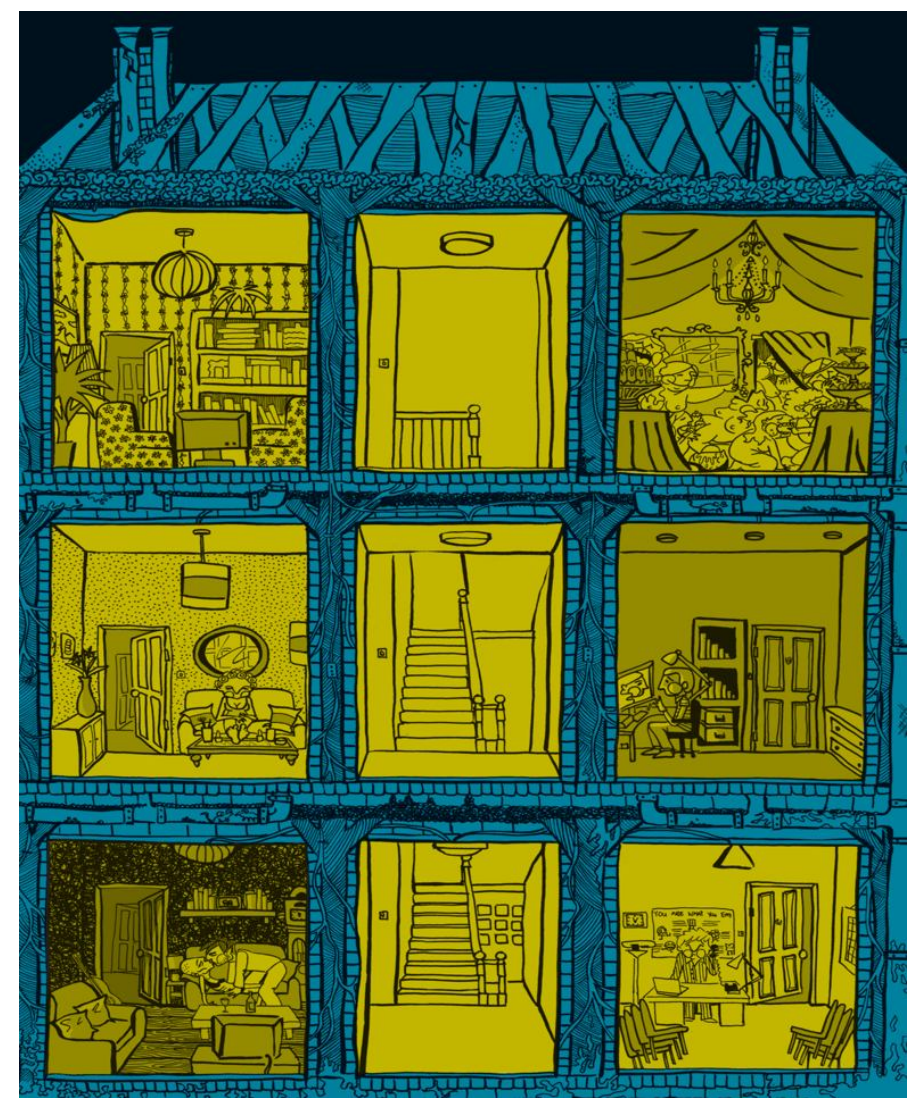

Figure 2: The inside cover of The House that Groaned by Karrie Fransman.

As a hybrid art form which coalesces words and images, comics provide a material manifestation of the social body. Each inhabitant brings out a unique aspect of the house. Through Barbara, the concealed dilapidation of the house is exposed as opposed to its superficial charm. Collating Barbara's self-beautification routines with the renovation of the house, the author makes a creative attempt to foreground the practice of concealment and secrecy which is characteristic of the Victorian society, in particular. While the book begins with an intricate visual narration of Barbara's beautifying methods of painting her lips in similitude with painting the house; putting earrings as to fixing the light bulb; waxing off unwanted hair as to pasting new wallpaper; manicuring her nails and polishing the furniture, it implies the authorial decision of reminding the reader that the house is also an integral character (see Figure 3). Presented in a conventional three by three format, such a narration also fortifies the just allocation of the house as the ultimate instance of Victorian ideals of beauty which gave unreasonable significance to outward beauty regardless of the inner charm. 


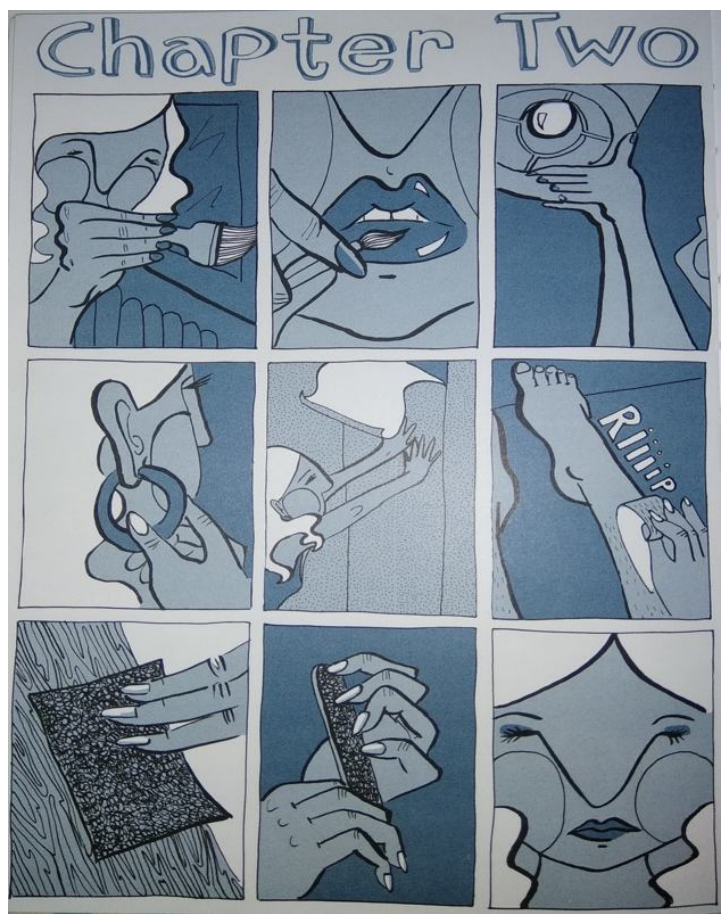

Figure 3: Barbara's attempt to beautify herself and the house in The House that Groaned by Karrie Fransman.

Interestingly, the author while tracing the past of its characters also traces the construction of the house from the second chapter onwards. The monochromatic grey pages with occasional spaces of white portray the characters' past. The construction of the house from 1865 to May 1989 is intertwined with the past of each character, signaling the complementary relationship shared by the characters against the backdrop of commercialization. In essence, the mansion shelters the distresses and oddities of its inmates like the book which houses the larger social anxieties within it. The house which reaches its inevitable doom towards the end of the narrative also parallels with Edgar Allan Poe's The Fall of the House of Usher, a gothic story on Roderick Usher's hyperesthesia and the subsequent disintegration of his mansion.

\section{Conclusion}

Exposing the catastrophic ideological interspaces between culture and corporeality, Fransman's The House That Groaned demonstrates the residuary of Victorian morality in the contemporary times. The graphic narrative through its dimly lit grey pages captures the cultural phantoms of the Victorian era in the twenty-first century western society which is plagued by an increasing rate of eating disorders. Though the graphic narrative, as the author states, was "inspired by Connell's idea that our individual bodies are 'canvases' on which the larger anxieties of the social body are reproduced" (The Body as a Canvas in Comics, 2012), it also potently maps the cultural consternation on a material level and the role of Victorian cult in the development of eating disorders. Exploring the foreboding and disquieting aspects which inheres an ideal female body, The House That Groaned deftly illustrates feminine anxieties, fancies, and fears through its characters. Through Janet, the tormented dietician, the graphic narrative presents a fine critique of the Victorian construct that proffered irrelevant significance to beauty and body perfection which eventually engendered many disruptive psychosomatic disorders. Similarly, by satirizing the Victorian practice of following restrictive eating to maintain physical charm, the author deploys Marion's character as the manifestation of women's yearning for a socio-cultural and 
corporeal liberation. In essence, through its inhabitants the house reflects the larger western society which is nearing a cultural doom because of its inherent ideological contradictions. To conclude, Fransman's The House That Groaned graphically emulates the negative impact of archaic Victorian cultural ideations that continues to destabilize health conceptions even in the contemporary era.

\section{References}

Bordo, S. (1993). Unbearable weight: feminism, western culture, and the body. Berkeley: University of California Press.

Bordo, S. (1997). The body and the reproduction of femininity. In K. Conboy, N. Medina, \& S. Stanbury (Eds.), Writing on the body: Female embodiment and feminist theory. New York, NY: Columbia University Press. 90-113.

Brumberg, J. J. (1988). Fasting girls: The emergence of anorexia nervosa as a modern disease. Cambridge: Harvard University Press.

Brumberg, J. J. (1997). The body project: An intimate history of American girls. New York: Random House.

Chou, H. C. (2011). "The appetite as voice": Gerty, food, and anorexia. Concentric: Literary and Cultural Studies, 37 (2), 187-216.

Fransman, K. (2012). The house that groaned. London: Square Peg Random House.

Fransman, K. (2012, Feb 16). Karrie Fransman: The house that groaned. (R. Alderson, Interviewer). It's Nice That. Retrieved from https://www.itsnicethat.com/articles/karrie-fransman-the-house-that-groaned

Fransman, K. [Karenfransman]. (2012, Feb 20). The body as a canvas in comics. [Video file]. https://www.youtube.com/watch?v=bCbg-XjNxro

Lupton, D. (1996). Food, the body, and the self. London: Sage.

Maggio, J. (2007). Comics and cartoons: A democratic art-form." PS: Political Science E Politics. 40(2), 237239.

Malson, H. M., \& Ussher, J. M. (1997). Beyond this mortal coil: Femininity, death and discursive constructions of the anorexic body. Mortality, 2(1), 43-61.

Michie, H. (1990). The flesh made word: Female figures and women's bodies. London: Oxford University Press.

Orbach, S. (1978). Fat is a feminist issue: The anti-diet guide to permanent weight loss. New York: Paddington Press.

Poe, E. A., \& Eric W. C. (1971). The fall of the house of usher. Ohio: Merrill.

Wolf, N. (1991). The beauty myth: How images of beauty are used against women. London: Vintage.

Dr. Sathyaraj Venkatesan is an Assistant Professor of English in the Department of Humanities and Social Sciences at the National Institute of Technology, Tiruchirappalli. He received Ph. D from the Indian Institute of Technology (IIT), Kanpur. He was a Fellow at the School of Criticism and Theory at Cornell University, New York and currently, an International Field Bibliographer with the Publications of Modern Language Association of America (PMLA). He is the author of The Idea and Practice of Reading (2018, Springer; forthcoming) with R. Joseph Ponniah, Edgar Allan Poe: Tales and Other Writings (2017, Orient Black Swan), AIDS in Cultural Bodies: Scripting the Absent Subject (1980-2010) (2016, Cambridge Scholars Publishing) with Gokulnath Ammanathil and Mapping the Margins: A Study of Ethnic Feminist Consciousness in Toni Morrison's Novels (2011).

Anu Mary Peter is a Ph.D. graduate student in the Department of Humanities and Social Sciences at the National Institute of Technology, Tiruchirappalli, India. Her ongoing Ph. D dissertation concentrates on eating disorders and graphic medicine. Besides her interest in photography, she is the author of a collection of poems titled: My Impossible Highway (2015, Partridge India). 